Supplement of The Cryosphere, 11, 2997-3009, 2017

https://doi.org/10.5194/tc-11-2997-2017-supplement

(C) Author(s) 2017. This work is distributed under

the Creative Commons Attribution 3.0 License.

(c) (1)

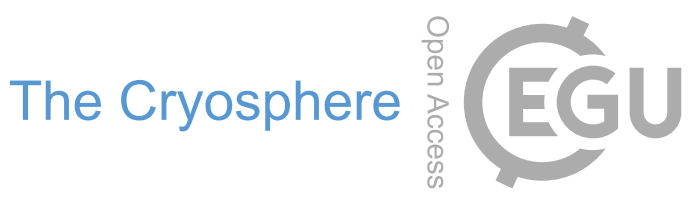

Supplement of

\title{
Measuring snow water equivalent from common-offset GPR records through migration velocity analysis
}

James St. Clair and W. Steven Holbrook

Correspondence to: James St. Clair (jstclair@uidaho.edu)

The copyright of individual parts of the supplement might differ from the CC BY 3.0 License. 
In addition to the data presented in the main text, we include snow density profiles for Pits 1-4 (Figure S1) and show data and results for GPR lines 2, 3, 5 and 6:

Line 2 is a skier pulled data set collected on February 25, 2015 in sub-freezing conditions. Pit 2 was located at $x=100$ meters. After interpolating the data to equal spacing, the trace spacing was 0.027 meters. The data and velocity picks are depicted in Fig S2 and the resulting snow depth, density and SWE estimates are shown in Fig S3.

Line 3 is a snowmobile driven data set collected on February 25, 2015 in sub-freezing conditions. Pit 2 was located at $x=54$ meters. After interpolating the data to equal spacing, the trace spacing was 0.027 meters. The data and velocity picks are depicted in Fig S4 and the resulting snow depth, density and SWE estimates are shown in Fig S5. Notably, Pit 2 was located $\sim 1.5$ meters off of the GPR line, which we suggest explains the discrepancy in the depth and SWE predictions at the pit site.

Line 5 is a snowmobile driven data set collected on March 17, 2015 in above-freezing conditions. Air temperature reached $10^{\circ} \mathrm{C}$ on this day and we infer that the dry snow assumption was not valid. After interpolating the data to equal spacing, the trace spacing was 0.0245 meters. The data and velocity picks are depicted in Fig S6 and the resulting snow depth, density and SWE estimates are shown in Fig S7. We probed snowdepth along this line at 2 meter intervals.

Line 5 is a snowmobile driven data set collected on March 17, 2015 in above-freezing conditions. Air temperature reached $10^{\circ} \mathrm{C}$ on this day and we infer that the dry snow assumption was not valid. After interpolating the data to equal spacing, the trace spacing was 0.0148 meters. The data and velocity picks are depicted in Fig S8 and the resulting snow depth, density and SWE estimates are shown in Fig S9. We probed snowdepth along this line at 2 meter intervals. 

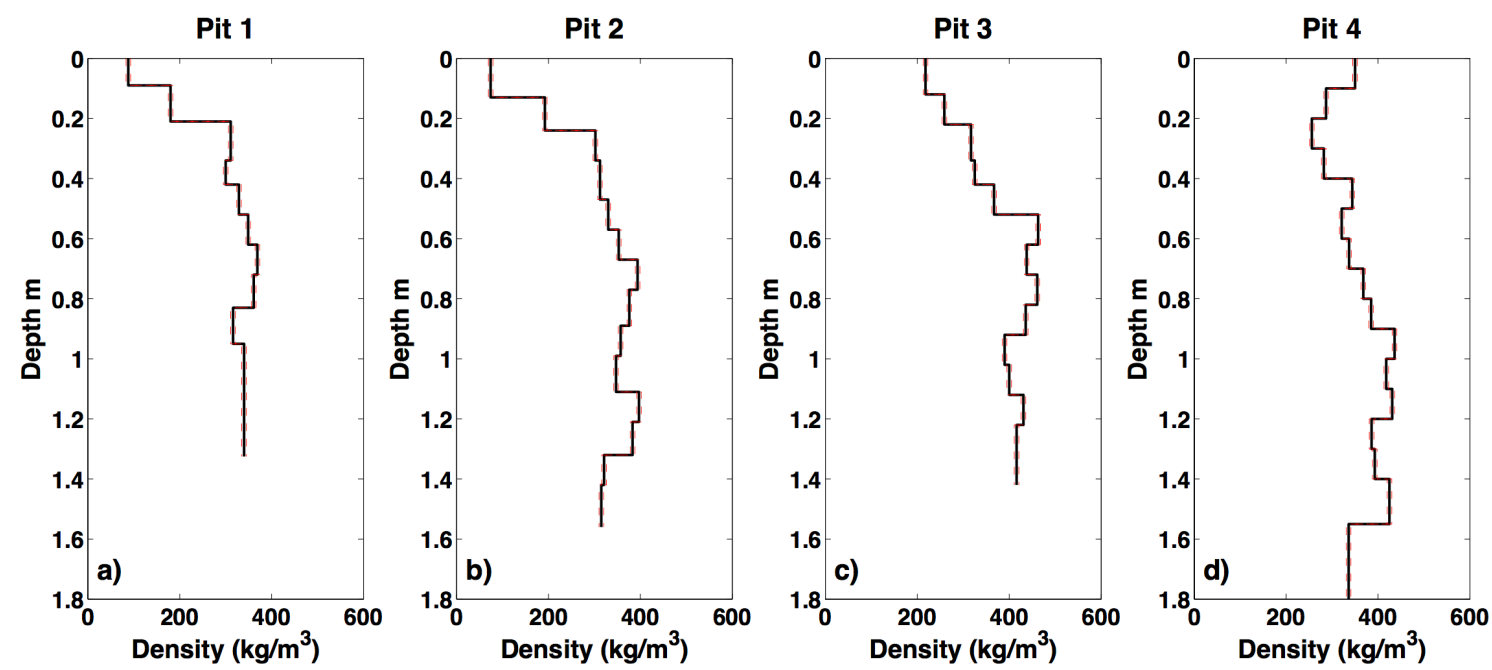

Figure S1. Snow density profiles. Black lines are measured density values, red lines indicate uncertainty estimate.
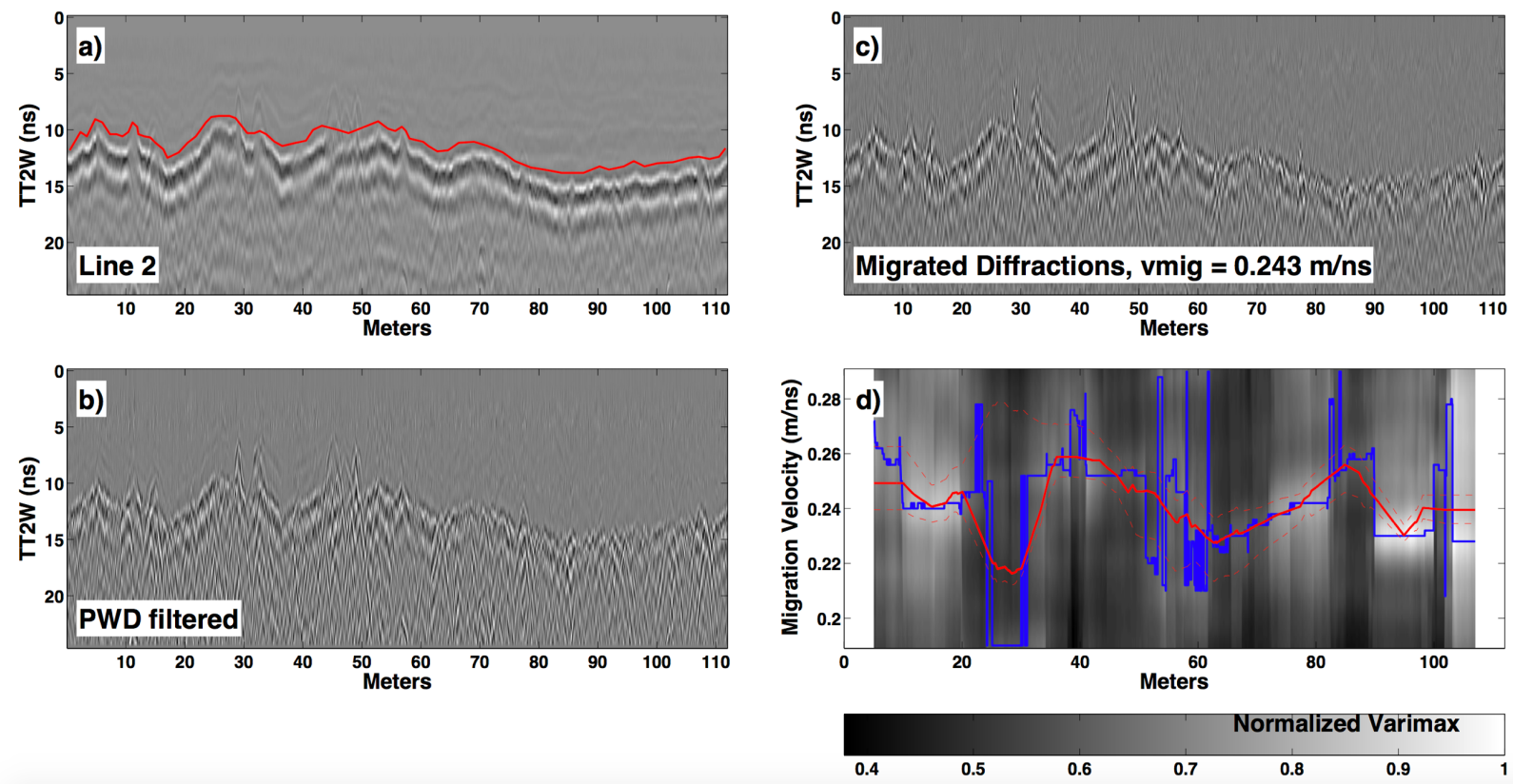

Figure S2. a) raw GPR data for Line, red line indicates interpreted ground reflection 2 b) GPR data after PWD filtering $c)$ diffractions migrated at the mean velocity $(0.243 \mathrm{~m} / \mathrm{ns})$ for the entire line d) Normalized varimax curves for sliding window 10 meters wide. Blue curve shows the peak value for every curve, red line is smoothed with a box car averaging filter 10 meters wide. 

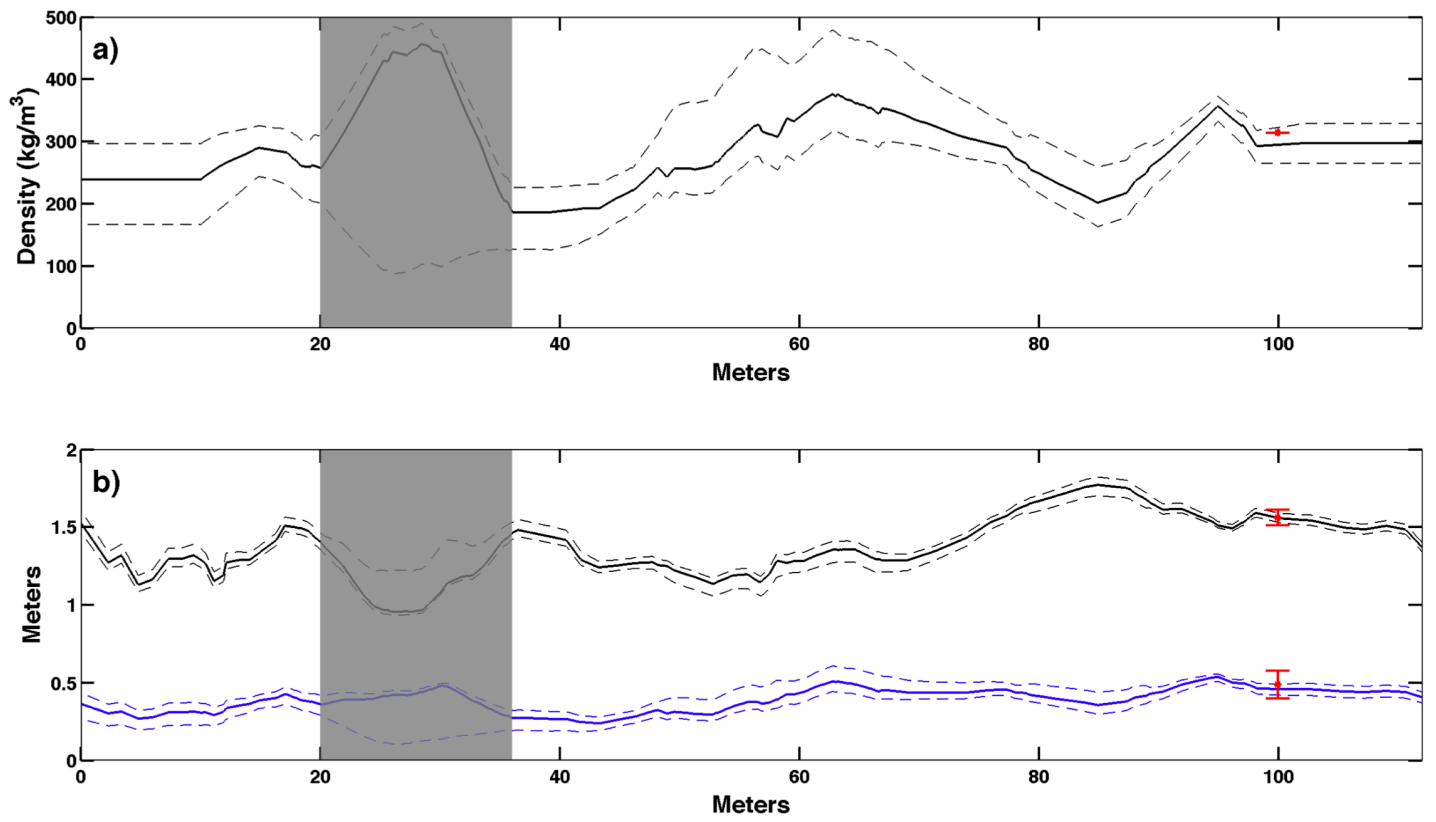

Figure S3. Line 2 Results. a) density, b) snow depth (black line) and SWE (blue line) estimates from the GPR data, snow pit data are shown in red. Grayed out region corresponds to areas where velocity picks are unreliable. 

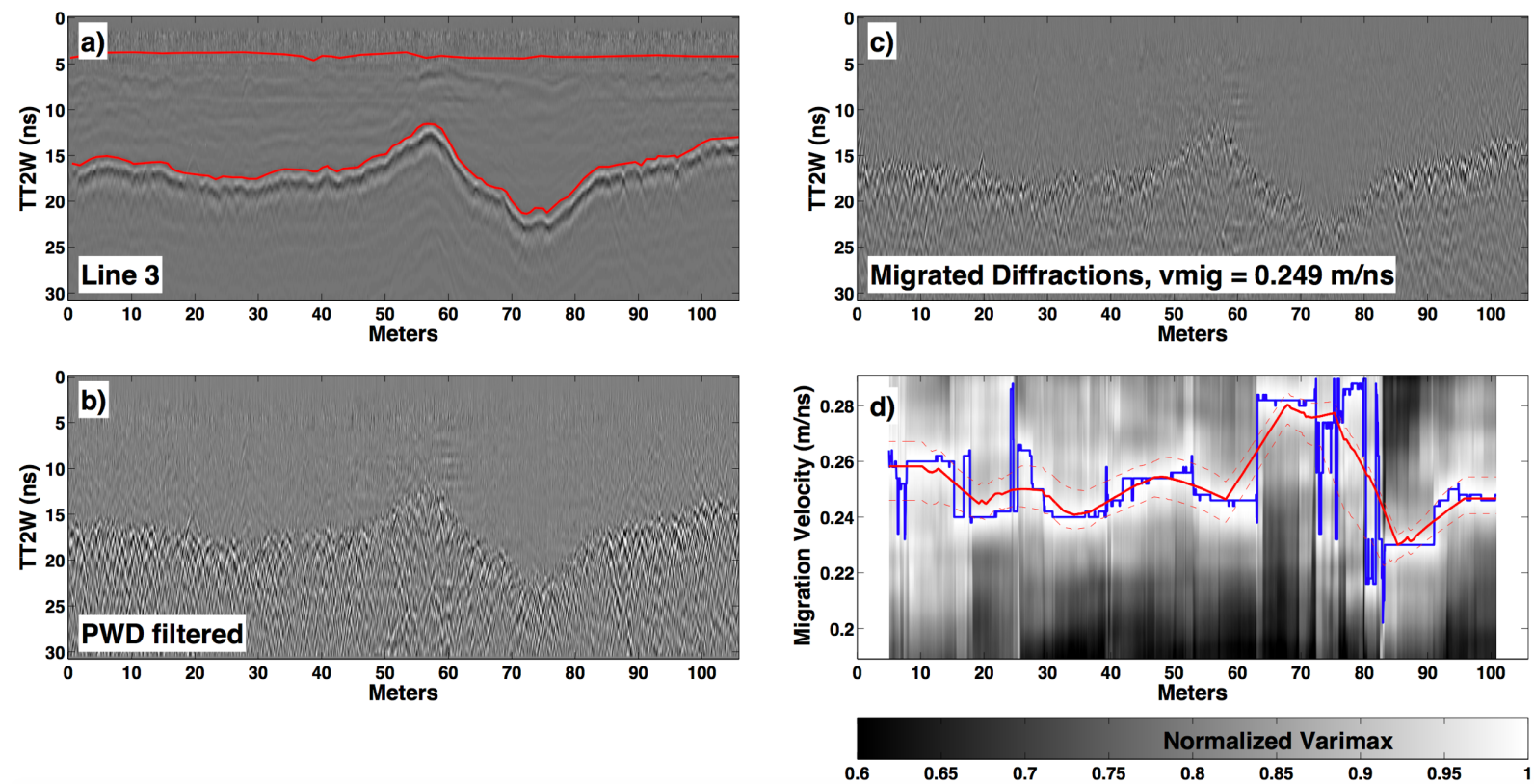

Figure S4. a) raw GPR data for Line 3, red lines indicates interpreted ground and snow reflections b) GPR data after PWD filtering c) diffractions migrated at the mean velocity $(0.247$ $\mathrm{m} / \mathrm{ns}$ ) for the entire line d) Normalized varimax curves for sliding window 10 meters wide. Blue curve shows the peak value for every curve, red line is smoothed with a box car averaging filter 10 meters wide.
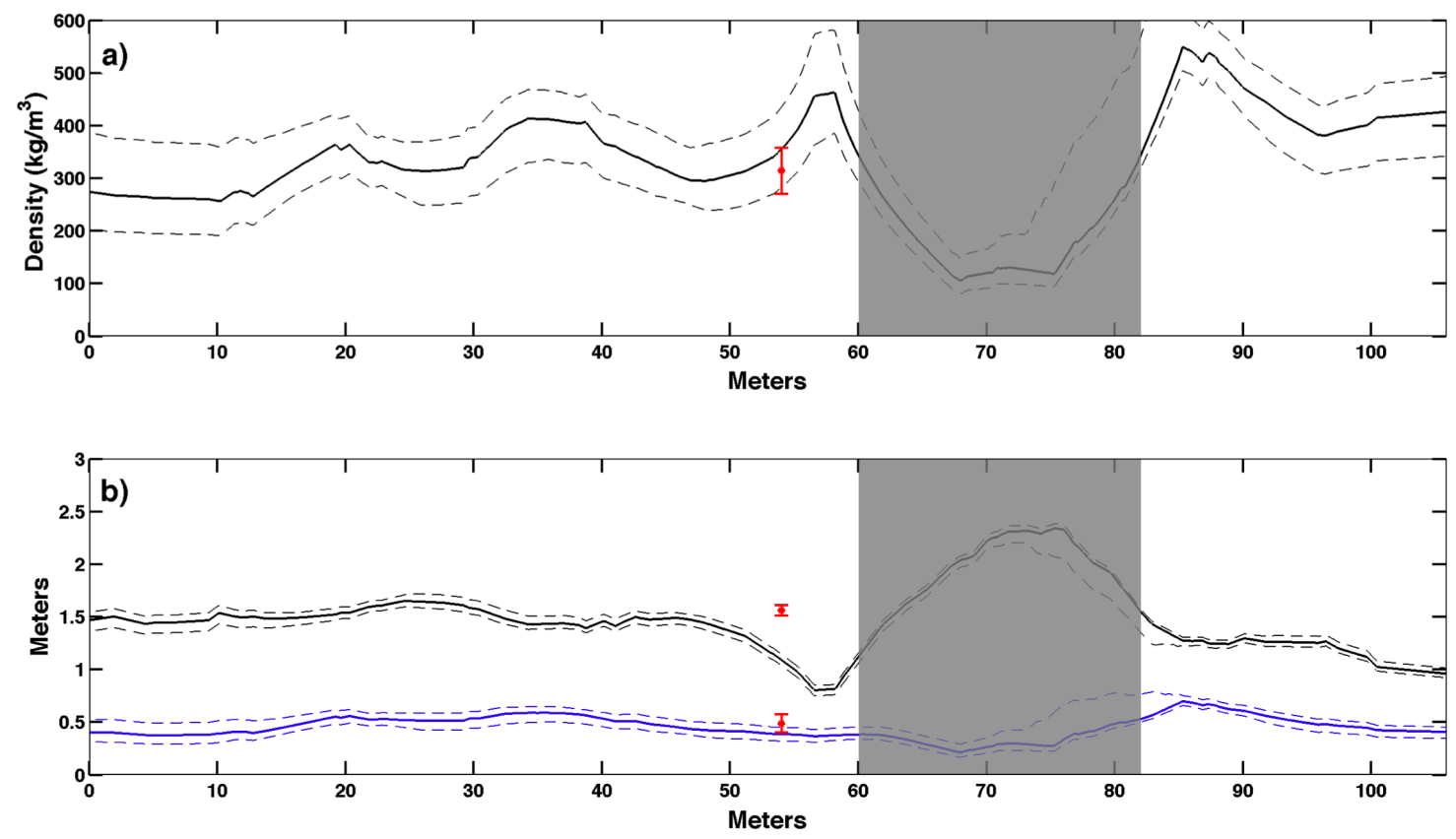

Figure S5. Line 3 Results. a) density, b) snow depth (black line) and SWE (blue line) estimates from the GPR data, snow pit data are shown in red. Grayed out region corresponds to areas where velocity picks are unreliable. 

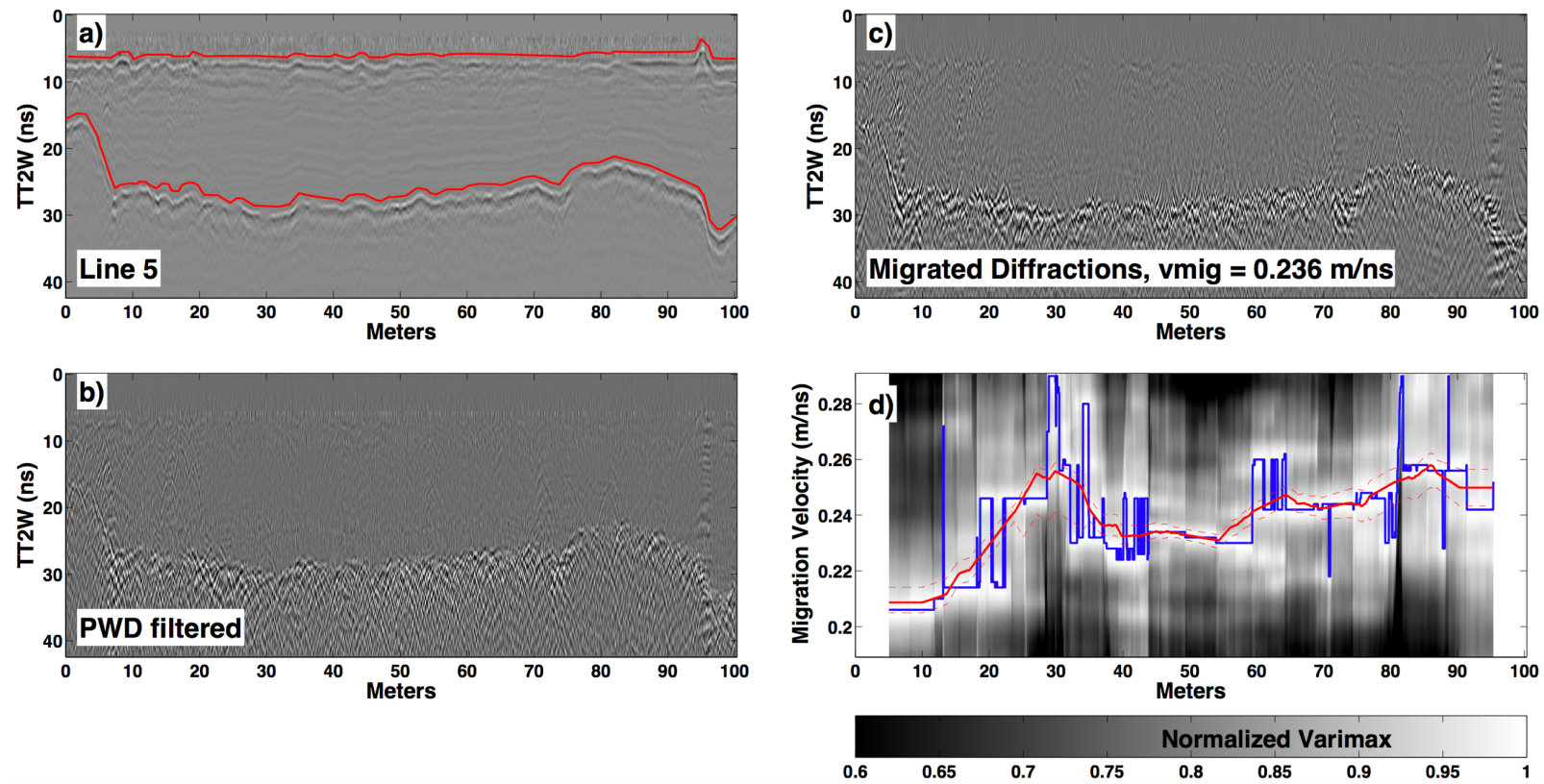

Figure S6. a) raw GPR data for Line 5, red lines indicates interpreted ground and snow reflections b) GPR data after PWD filtering c) diffractions migrated at the mean velocity $(0.233$ $\mathrm{m} / \mathrm{ns}$ ) for the entire line d) Normalized varimax curves for sliding window 10 meters wide. Blue curve shows the peak value for every curve, red line is smoothed with a box car averaging filter 10 meters wide.
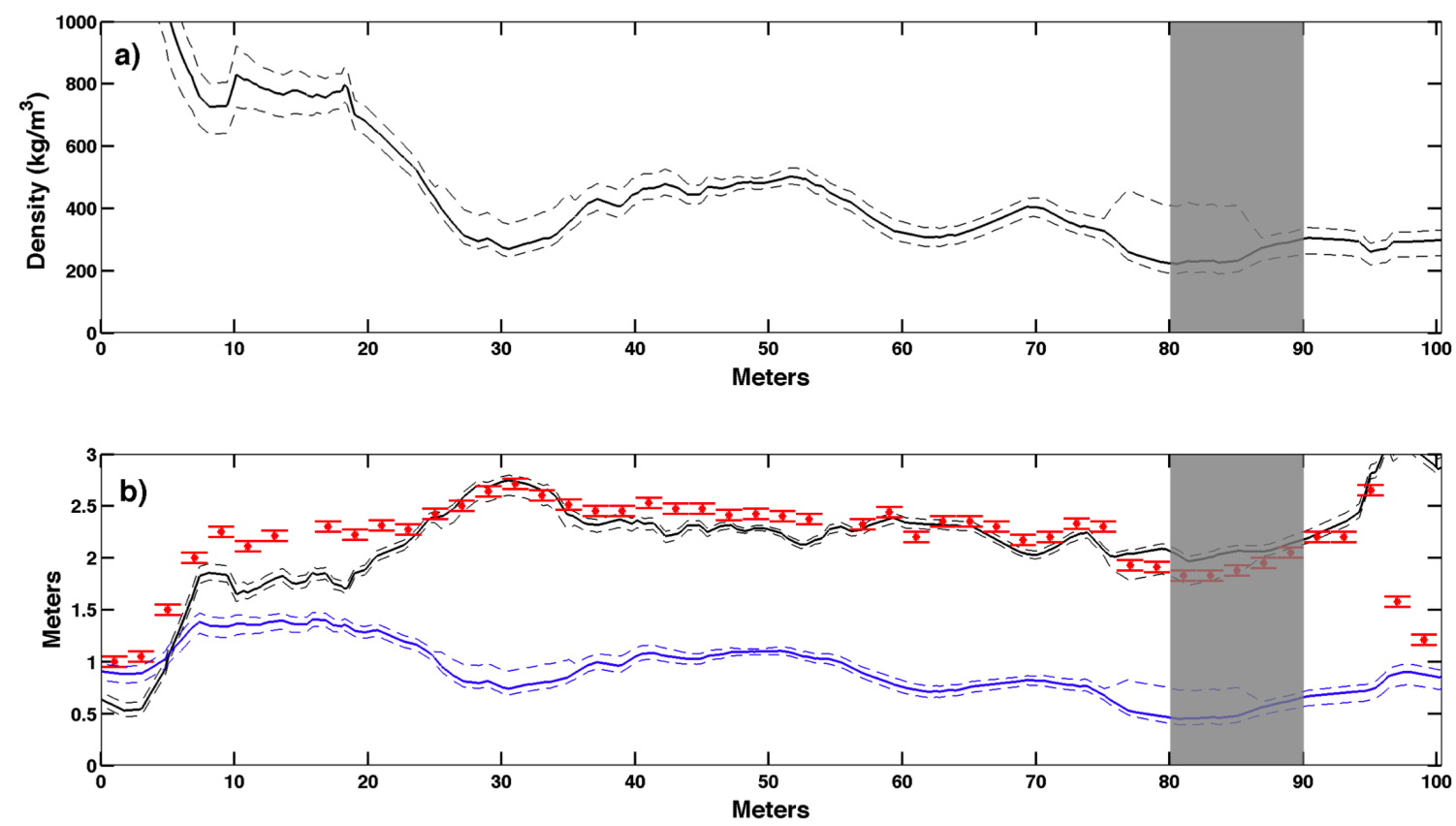

Figure S7. Line 5 Results. a) density, b) snow depth (black line) and SWE (blue line) estimates from the GPR data, snow pit data are shown in red. Grayed out region corresponds to areas where velocity picks are unreliable. 

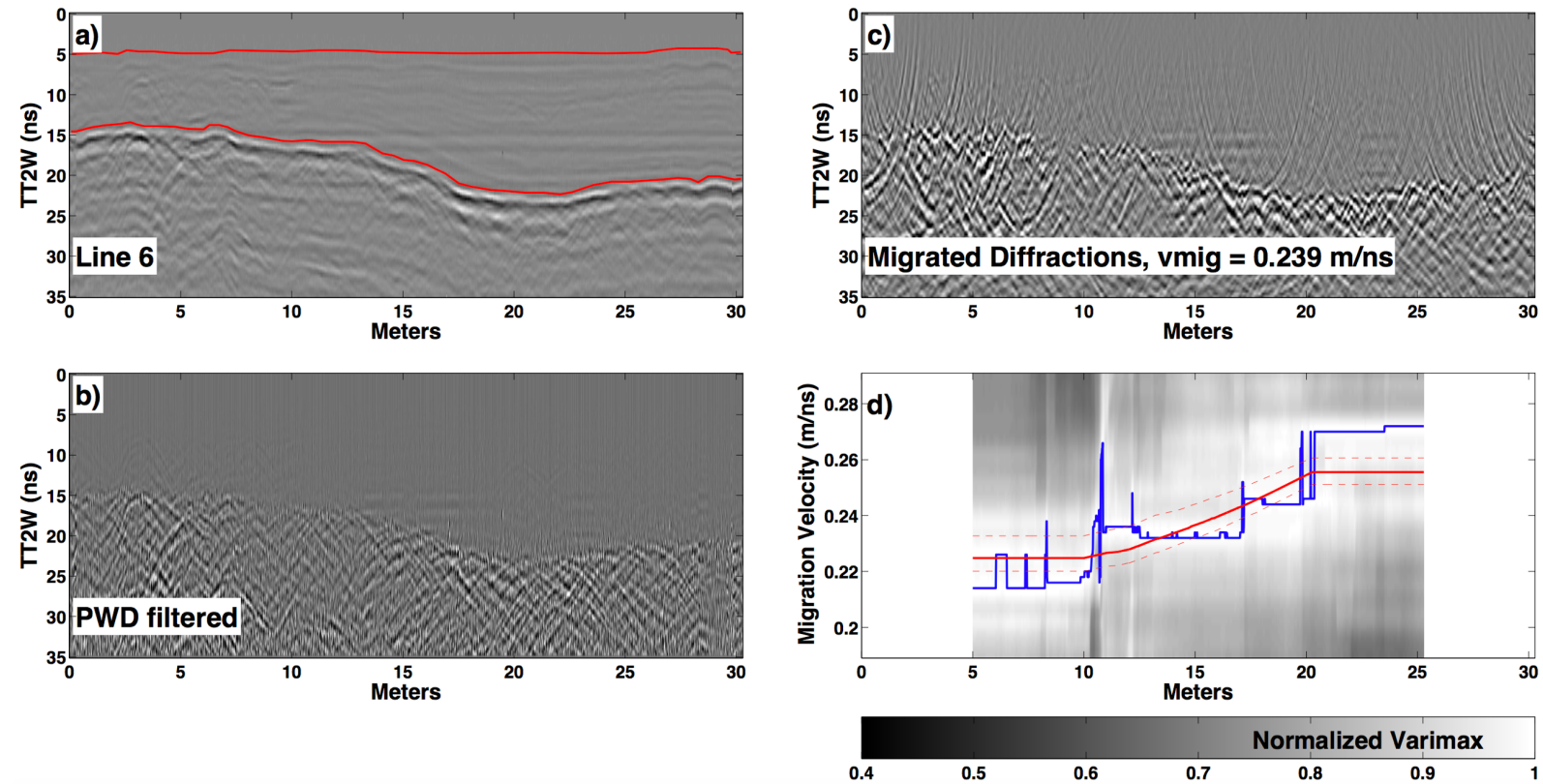

Figure S8. a) raw GPR data for Line 6, red lines indicates interpreted ground and snow reflections b) GPR data after PWD filtering c) diffractions migrated at the mean velocity $(0.245$ $\mathrm{m} / \mathrm{ns}$ ) for the entire line d) Normalized varimax curves for sliding window 10 meters wide. Blue curve shows the peak value for every curve, red line is smoothed with a box car averaging filter 10 meters wide.
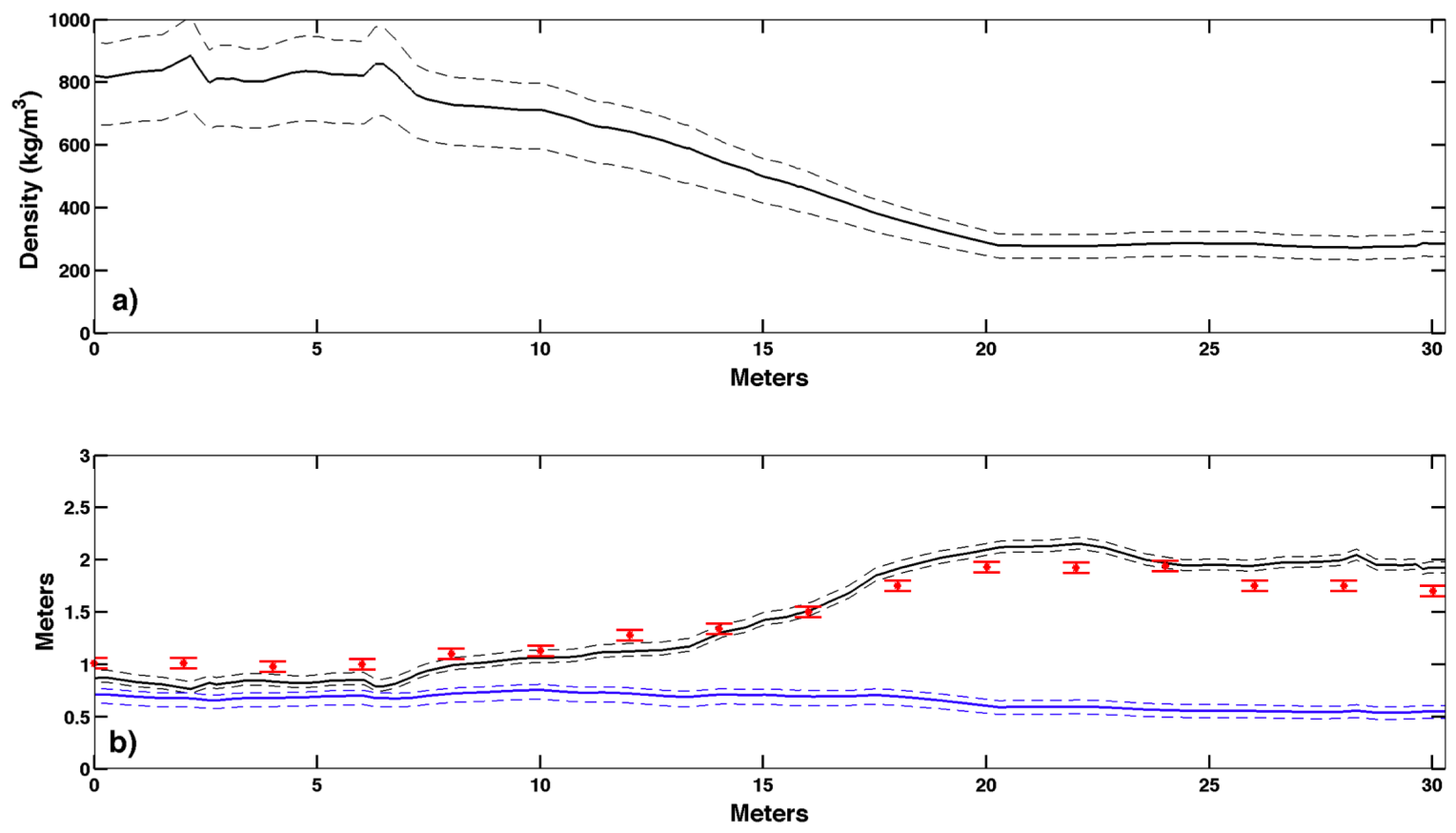

Figure 59. Line 6 Results. a) density, b) snow depth (black line) and SWE (blue line) estimates from the GPR data, snow pit data are shown in red. 